\title{
Martensitic transformation of individual grains in low-alloyed TRIP steels
}

\author{
E. Jimenez-Melero, ${ }^{\mathrm{a}, *}$ N.H. van Dijk, ${ }^{\mathrm{a}}$ L. Zhao, ${ }^{\mathrm{b}}$ J. Sietsma, ${ }^{\mathrm{b}}$ S.E. Offerman, ${ }^{\mathrm{b}}$ \\ J.P. Wright ${ }^{c}$ and S. van der Zwaag ${ }^{\mathrm{d}}$ \\ ${ }^{a}$ Fundamental Aspects of Materials and Energy, Faculty of Applied Sciences, Delft University of Technology, Mekelweg 15, \\ 2629 JB Delft, The Netherlands \\ ${ }^{\mathrm{b}}$ Department of Materials Science and Engineering, Delft University of Technology, Mekelweg 2, 2628 CD Delft, The Netherlands \\ ${ }^{\mathrm{c}}$ European Synchrotron Radiation Facility, 6 Rue Jules Horowitz, BP 220, 38043 Grenoble Cedex, France \\ ${ }^{\mathrm{d}}$ Faculty of Aerospace Engineering, Delft University of Technology, Kluijverweg 1, 2629 HS Delft, The Netherlands
}

Received 9 October 2006; accepted 25 October 2006

Available online 6 December 2006

\begin{abstract}
We have performed in situ synchrotron X-ray diffraction experiments on low-alloyed multiphase TRIP steels during cooling, to monitor the martensitic transformation of individual austenite grains within the bulk material. Direct experimental evidence is presented that the stability of the austenite grains is controlled not only by the local carbon level but also by the grain size. This new quantitative information on the martensitic transformation in complex microstructures is of great importance for the design of martensite-based metallic materials.
\end{abstract}

(C) 2006 Acta Materialia Inc. Published by Elsevier Ltd. All rights reserved.

Keywords: Iron alloys; Metastable phases; Martensitic phase transformation; X-ray diffraction; Synchrotron radiation

Materials scientists invest a lot of effort in designing and developing composite materials with optimum mechanical properties for existing and novel technological applications [1]. New heterogeneous materials with optimized combinations of constituent phases present in a grain-refined microstructure now lead the field [2-5]. The overall mechanical properties of such materials are normally estimated as a combined effect of the average characteristics of each phase. However, a precise optimization requires a detailed knowledge of processes at the level of individual grains. In this sense, low-alloyed TRIP steels constitute a model multiphase metallic system with a clear need for information on the behaviour of individual grains. These materials are attracting increasing interest within the automotive industry due to their remarkably large elongation values, while retaining high-strength characteristics. Such elongation is mainly achieved by making use of the transformationinduced plasticity (TRIP) effect, which refers to the increase in plasticity caused by the martensitic transfor-

\footnotetext{
* Corresponding author. Tel.: +31 15 2781192; fax: +31 15 2788303; e-mail: E.Jimenez-Melero@tudelft.nl
}

mation of the retained high-temperature austenite phase, which is tailored to be metastable at room temperature $[6,7]$. The martensitic transformation can be either thermally activated or induced by an applied stress.

The TRIP steel (chemical composition: $0.218 \mathrm{wt} . \% \mathrm{C}$, 1.539 wt. $\%$ Mn, 0.267 wt. $\%$ Si, 1.750 wt. $\%$ Al, 0.018 wt. $\%$ $\mathrm{P}$, balance $\mathrm{Fe}$ ) was annealed at $1173 \mathrm{~K}$ for $30 \mathrm{~min}$, subsequently quenched to a temperature of $673 \mathrm{~K}$ where it was held for $60 \mathrm{~s}$, and finally quenched to room temperature. The resultant multiphase microstructure comprises ferrite, bainite and metastable austenite (Fig. 1). In lowalloyed TRIP steels, the bainite phase shows a carbidefree structure of small ferrite plates, together with very fine intermediate austenite grains with a diameter below $1 \mu \mathrm{m}$. Depending on the bainitic transformation kinetics, non-transformed fractions of the original austenite grains can be preserved during subsequent cooling to room temperature (Fig. 1 inset).

We have assessed the stability of individual austenite grains by using the state-of-the art three-dimensional synchrotron X-ray diffraction microscope [8]. A monochromatic X-ray beam with an energy of $80 \mathrm{keV}$ and a beam size of $28 \times 29 \mu \mathrm{m}^{2}$ illuminated the cylindrical sample with a diameter of $0.50 \mathrm{~mm}$. The scattered 


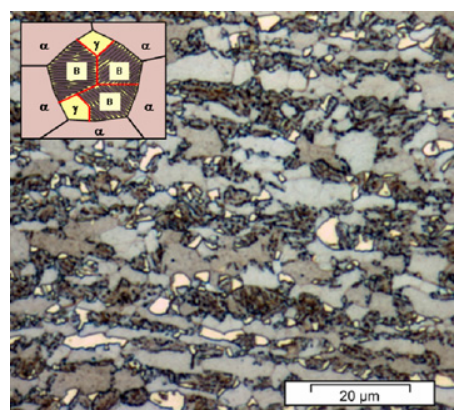

Figure 1. Optical micrograph of TRIP steel. The room-temperature multiphase microstructure contains a metastable austenite phase (white) within a matrix of ferrite (grey) and bainite (dark grey) phases. The inset shows the schematic microstructure with the austenite $(\gamma)$, ferrite $(\alpha)$ and bainite (B) phases, where the black lines indicate the microstructure formed during the annealing at $1173 \mathrm{~K}$, and the red lines the phase boundaries formed in the subsequent cooling to room temperature.

intensity was recorded on a two-dimensional detector placed behind the sample (80\% transmission). During a 2 s exposure the sample was continuously rotated around the vertical sample axis over an angle of $0.5^{\circ}$. A total angular rotation range from $-30^{\circ}$ to $+30^{\circ}$ was covered. The grains that fulfilled the Bragg condition generated a diffraction spot on the detector. The integrated intensity of each diffraction spot is directly proportional to the grain volume from which it originated [9]. To validate whether the grains were completely illuminated, additional scans with a larger beam size of $39 \times 39 \mu \mathrm{m}^{2}$ were performed. By combining the 2D diffraction patterns for all the monitored rotation angles, a 3D dataset was obtained. A 3D peak fit procedure allowed the accurate determination of the grain volume as well as the lattice parameter, and hence the carbon concentration [10], of the individual austenite grains.

Figure $2 \mathrm{a}$ shows the resulting diffraction pattern at room temperature. The stability of the austenite grains

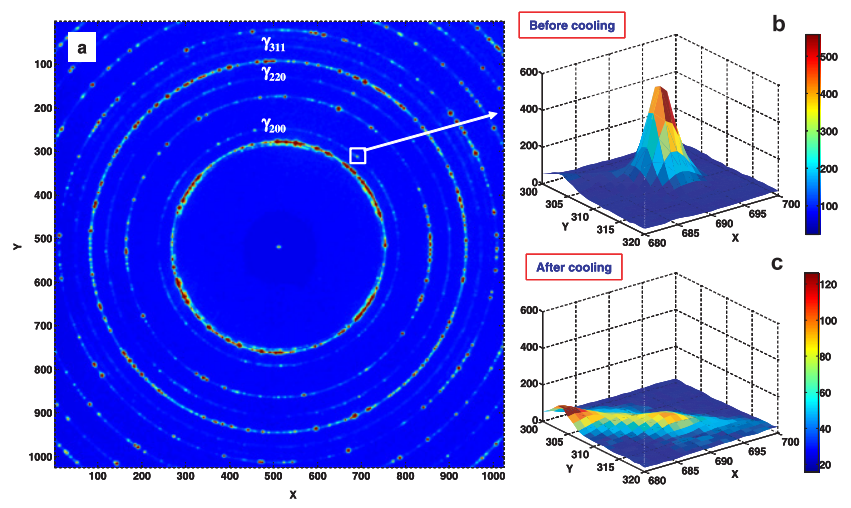

Figure 2. X-ray diffraction pattern of TRIP steel. (a) The pattern at room temperature shows both ferrite and austenite reflections on separate diffraction rings. Single spots originating from individual grains appear within the mentioned rings. The $\{200\},\{220\}$ and $\{311\}$ austenite diffraction rings, whose single spots have been analysed in this study, are denoted in the figure as $\gamma_{200}, \gamma_{220}$ and $\gamma_{311}$, respectively. (b) A single austenite diffraction peak from the $\{200\}$ ring at room temperature before cooling. (c) The same region as in (b) after cooling the sample to $100 \mathrm{~K}$ and heating back to room temperature. can be determined by exposing the TRIP steel to a mechanical or thermal load. For reasons of improved experimental accuracy, we have chosen the latter. We cooled the material from room temperature to $100 \mathrm{~K}$ in steps of $20 \mathrm{~K}$, while recording the diffraction pattern at each temperature step. In this way, we destabilize the austenite and promote its transformation into martensite, via an increase in the chemical driving force for the transformation [11]. Using this approach, the stability of individual austenite grains can be adequately monitored in situ. No time dependence was observed for the martensitic transformation of the metastable austenite grains, indicating that the monitored microstructure is defined by the lowest temperature reached. In Figure $2 \mathrm{~b}$ a single austenite diffraction spot is considered in detail. As shown in Figure 2c, this spot has vanished after cooling the sample to $100 \mathrm{~K}$, indicating that the corresponding austenite grain has transformed into martensite during cooling. By contrast, a powder diffraction ring forming a background ridge in Figure $2 \mathrm{~b}$ and $\mathrm{c}$ remains unaffected. This powder diffraction ring originates from austenite grains with a size below the detection limit for individual grains of $5 \mu^{3}$.

In Figure 3, the grain volume of several individual austenite grains is shown as a function of temperature during cooling. Three different forms of transformation behaviour have been observed. Most of the austenite grains $(77 \%)$ transform completely into martensite in a single temperature step (Fig. 3a). However, a few
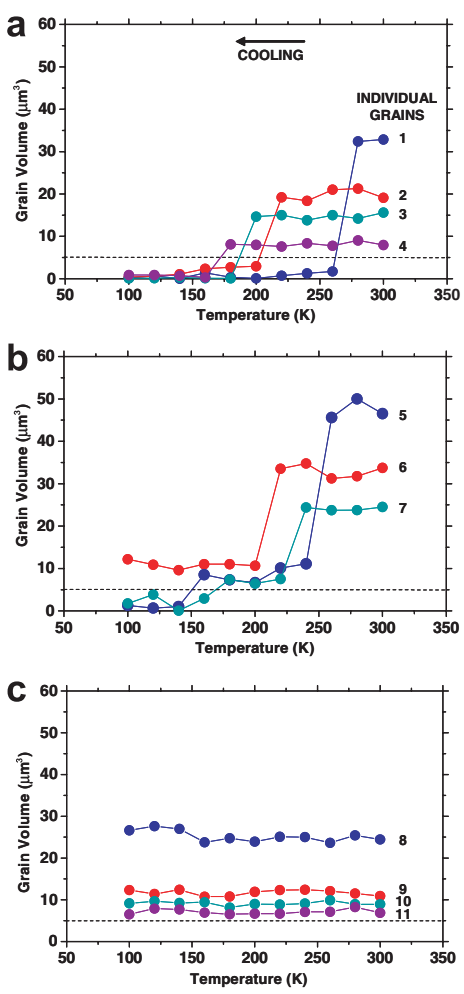

Figure 3. Observed transformation behaviours of individual austenite grains: (a) Grains (77\%) that completely transform into martensite in a single temperature step (1-4). (b) Grains (4\%) that partly transform into martensite (5-7). For some of these grains, a second transformation is observed at lower temperatures $(5,7)$. (c) Grains $(19 \%)$ that remain stable during cooling to $100 \mathrm{~K}(8-11)$. The detection limit for individual grains is indicated by the dashed lines. 
austenite grains (4\%) show an incomplete transformation, where only part of the austenite grain transforms into martensite (Fig. 3b). Some of these grains show a second transition at a lower temperature. Finally, a significant amount of austenite grains $(19 \%)$ do not show any transformation down to $100 \mathrm{~K}$ (Fig. 3c). The large variation in the observed transformation behaviour of the individual austenite grains during cooling indicates that the stability of the grains strongly differs from grain to grain. The grains without any transformation appear to have the highest stability. The few grains with an incomplete transformation or a two-step process most probably indicate two independent retained austenite grains with the same crystallographic orientation. These two retained austenite grains with a different stability can originate from a single austenite grain that existed during the annealing at $1173 \mathrm{~K}$, and which was split up by the formation of bainite (see Fig. 1 inset). They have therefore been treated as two independent austenite grains throughout this study. However, it cannot be totally excluded that the incomplete transformation is caused by variations in stability within a single grain.

Seventy individual austenite grains have been analyzed in order to derive the first quantitative experimental data on the stabilizing effects of both the carbon content and the grain size on the retained austenite in TRIP steels. The austenite stability is characterized by its martensitic transformation temperature $\left(M_{\mathrm{S}}\right)$. Figure $4 \mathrm{a}$ displays the austenite lattice parameter and the corresponding carbon content, as a function of the austenite grain size at room temperature. During the annealing at $1173 \mathrm{~K}$, a homogeneous carbon content of $0.42 \mathrm{wt} . \%$ was estimated to be present in the austenite grains. At room temperature all austenite grains show an enhanced carbon content, indicating the carbon enrichment of the individual austenite grains during the holding period of $60 \mathrm{~s}$ at $673 \mathrm{~K}$ due to the formation of bainite. Furthermore, an overall trend of increasing carbon concentration for smaller austenite grains is clearly observed. This trend indicates that when a larger amount of bainite is formed in the original austenite grain, it is expected that the retained austenite grains in the final microstructure show a smaller grain volume, and concomitantly, a higher carbon content. During cooling from room temperature, the austenite grains with the lowest carbon content and the highest grain volume were found to show the lowest stability and to transform at a higher temperature into martensite. The carbon content is found to be the dominant parameter that governs the stability of the largest austenite grains. The dependence of the martensitic transformation temperature on the austenite grain volume is indicated in Figure $4 \mathrm{~b}$. The experimental data show that the stability of the austenite grains increases for decreasing grain volumes below $20 \mu^{3}$. The observed spread in the experimental data further highlights that other microstructural parameters, such us the grain geometrical shape, dislocation density or crystallographic orientation, seem to play a role as well. Even though slightly different values for the carbon content are obtained if a different lattice parameter-carbon content relationship is used, similar conclusions concerning the relative stability of the different austenite grains will be derived. Moreover, since no experimental evidence of a martensite phase has been found at
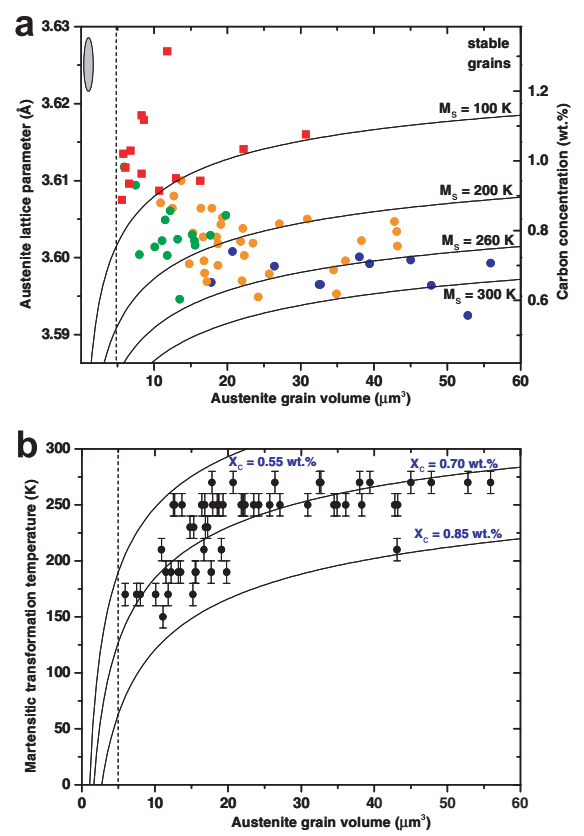

Figure 4. Effect of grain size and carbon content on the stability of austenite grains. (a) Lattice parameter and corresponding carbon content of the individual austenite grains as a function of their grain volume. The blue, orange, and green circles represent austenite grains that transform in the temperature range of $260<T<300 \mathrm{~K}$, $200<T<260 \mathrm{~K}$, and $100<T<200 \mathrm{~K}$, respectively. The red squares represent the austenite grains that remain stable during cooling to $100 \mathrm{~K}$. The grey area below the detection limit for individual grains (dashed line) represents the very small austenite grains with an experimental average carbon content of about $1.25 \mathrm{wt} . \%$. The solid lines represent the estimates of Eq. (3) for different constant martensitic transformation temperatures $\left(M_{\mathrm{S}}\right)$. The marker size corresponds to the experimental error. (b) Martensitic transformation temperature of the individual austenite grains as a function of their grain volume. The solid lines represent the estimates of Eq. (3) for different constant carbon contents $\left(X_{\mathrm{C}}\right)$.

room temperature before cooling the material to $100 \mathrm{~K}$ from the present synchrotron experiments, the stresses due to the previous quench from $673 \mathrm{~K}$ are expected to be relatively small.

The very small austenite grains, present between the bainite plates, have a size below the detection limit for individual grains. A powder analysis of the diffraction ring (Fig. 2) indicated that these very small grains constitute about 60 vol. $\%$ of the austenite phase at room temperature (before cooling), are strongly enriched in carbon and remain stable during cooling. This result is in line with the recent ex situ scanning electron microscopy (SEM) studies on the stress-induced martensitic transformation of TRIP steels, which indicate that these small grains do remain untransformed even at the onset of necking [12]. They are therefore not responsible for the TRIP effect in these low-alloyed steels.

In order to extract more generic information from these experimental data, we consider the change in Gibbs free energy of the grain $\Delta G$ for the austenite $(\gamma)$ to martensite $\left(\alpha^{\prime}\right)$ transformation [13]:

$\Delta G_{\text {grain }}^{\gamma \rightarrow \alpha^{\prime}}=-\Delta g_{\mathrm{v}} V_{\gamma}+\Delta g_{\mathrm{s}} V_{\gamma}+\Delta \sum_{j} S_{j} \sigma_{j}$,

where the first term on the right-hand side of the equation corresponds to the change in chemical free energy, 
which depends on both temperature and chemical composition, and the second term refers to the strain energy ( $\Delta g$ is the Gibbs free energy per unit volume). Both terms are proportional to the transforming austenite grain volume $\left(V_{\gamma}\right)$. The third term accounts for the change in interfacial energy due to the transformation, and is composed of the surface area $S_{j}$ and the surface free energy $\sigma_{j}$ of the $j$-interface. Moreover, $\Delta g_{\mathrm{v}}$ can be assumed to depend linearly on temperature $(T)$ and carbon content $\left(x_{\mathrm{C}}\right)$ in the temperature range from $100 \mathrm{~K}$ to $300 \mathrm{~K}$ and for carbon contents between $0.4 \mathrm{wt} . \%$ and $1.4 \mathrm{wt} . \%$ [14], so that:

$\Delta g_{\mathrm{v}}=\Delta g_{0}+\alpha T+\beta x_{\mathrm{C}}$,

where $\alpha=\mathrm{d} \Delta g_{\mathrm{v}} / \mathrm{d} T$ and $\beta=\mathrm{d} \Delta g_{\mathrm{v}} / \mathrm{d} x_{\mathrm{C}}$ correspond to the variation of the chemical free energy with temperature and carbon content, respectively.

The austenite grain will transform into martensite when $\Delta g$ exceeds a critical value [13]. Solving these equations for the critical value of $\Delta g$ leads to a martensitic transformation temperature $\left(M_{\mathrm{S}}\right)$ of the form:

$M_{\mathrm{S}}=M_{\mathrm{S} 0}-A x_{\mathrm{C}}-B V_{\gamma}^{-\frac{1}{3}}$.

The first two terms of this expression reflect the wellknown Andrews' empirical relationship between $M_{\mathrm{S}}$ and the carbon content $x_{\mathrm{C}}$ [15]. $M_{\mathrm{S} 0}$ depends on the alloying composition, and on internal stresses stemming from differences in thermal contraction between austenite and ferrite [10], or from the shear strain and the change in volume introduced by the martensitic transformation [11]. In the case of steels, $A$ has a value of $425 \mathrm{~K} / \mathrm{wt} . \%$ [15]. The third term in Eq. (3) indicates for the first time an additional dependence of $M_{\mathrm{S}}$ on the size of the austenite grain in a multiphase steel. For spherical grains, the prefactor $B$ in the grain volume term can be expressed as follows:

$B=\frac{(36 \pi)^{\frac{1}{3}}}{N_{0} \alpha} \Delta \sigma_{\gamma \rightarrow \alpha^{\prime}}$

where $\Delta \sigma_{\gamma \rightarrow \alpha^{\prime}}$ refers to the change in surface free energy caused by the martensitic transformation (assuming $S_{j}$ to be constant but the type of interface, and thus $\sigma_{j}$, to change), and $N_{0}$ stands for the atomic density of austenite $\left(N_{0}=8.57 \times 10^{28} \mathrm{~m}^{-3}\right)$. Thermodynamic calculations with the MTDATA database yield a value of $\alpha=1.1 \times 10^{-23} \mathrm{~J} /$ atom $\mathrm{K}$.

Estimates from Eq. (3) are displayed as solid lines in Figure $4 a$ and $b$. The best agreement with the experimental results has been obtained for $M_{\mathrm{S} 0}=702 \mathrm{~K}$ and $B=475 \mu \mathrm{m} \mathrm{K}$. Figure $4 \mathrm{a}$ shows that the drawn lines separate experimental data points belonging to different transformation temperature ranges. Figure $4 \mathrm{~b}$ reveals the existence of a minimum austenite grain size below which the martensitic transformation does not occur. This threshold value depends only weakly on the carbon content, and is found to be lower than $5 \mu \mathrm{m}^{3}$ for this TRIP steel. The change in surface free energy from ferrite/ austenite to ferrite/martensite has been reported to amount to $0.2 \mathrm{~J} / \mathrm{m}^{2}[16]$. The change in surface free energy derived from the experimental value of $B$ turns out to be two orders of magnitude larger. This discrepancy implies that a significant number of martensite plates is formed within one single austenite grain, so that there is additional surface energy generated through the large amount of new martensite/martensite interfaces. A comparison of the experimental data in Figure 4 with the estimates from Eq. (3) demonstrates that for large austenite grains $M_{\mathrm{S}}$ is mainly controlled by the carbon concentration, while for small grains the grain volume plays a dominant role.

Our synchrotron X-ray diffraction experiments have provided unique in situ information on the martensitic transformation of individual austenite grains within the ferritic matrix of TRIP steels. Since a significant number of austenite grains were simultaneously monitored with decreasing temperature, the influence of both the carbon content and grain volume on the stability of the individual austenite grains has been quantified independently. The results confirm the linear dependence of the martensitic transformation temperature $\left(M_{\mathrm{S}}\right)$ with the carbon content. However, an additional term has been introduced and quantified for the first time to account for the stabilization effect due to the austenite grain size. The resultant expression for $M_{\mathrm{S}}$ will be undoubtedly of great importance for tailoring the stability of retained austenite in TRIP steels for optimal mechanical properties. These individual-grain results can also be used as an input to validate and further improve the existing models of martensitic transformations. Consequently, a significant number of martensite-based heterogeneous materials can strongly benefit from these results.

We acknowledge the European Synchrotron Radiation Facility for provision of synchrotron radiation facilities and thank L. Margulies for assistance in using beamline ID11. This work was financially supported by the Netherlands Foundation for Fundamental Research on Matter (FOM) and the Netherlands Institute for Metals Research (NIMR).

[1] G.B. Olson, Science 277 (1997) 1237.

[2] G. He, J. Eckert, W. Löser, L. Schultz, Nat. Mater. 2 (2003) 33.

[3] P.M. Kelly, L.R. Francis Rose, Prog. Mater. Sci. 47 (2002) 463.

[4] A.M. Glezer, E.N. Blinova, V.A. Pozdnyakov, A.V. Shelyanov, J. Nanopart. Res. 5 (2003) 551.

[5] E. Clouet, L. Laé, T. Épicier, W. Lefebvre, M. Nastar, A. Deschamps, Nat. Mater. 5 (2006) 482.

[6] M. Militzer, Science 298 (2002) 975.

[7] P. Jacques, Q. Furnémont, A. Mertens, F. Delannay, Phil. Mag. 81 (2001) 1789.

[8] H.F. Poulsen, Three Dimensional X-ray Diffraction Microscopy, Springer, Berlin, 2004.

[9] B.E. Warren, X-ray Diffraction, Dover Publications, New York, 1990.

[10] N.H. van Dijk, A.M. Butt, L. Zhao, J. Sietsma, S.E. Offerman, J.P. Wright, S. van der Zwaag, Acta Mater. 53 (2005) 5439.

[11] M.R. Berrahmoune, S. Berveiller, K. Inal, A. Moulin, E. Patoor, Mater. Sci. Eng. A 378 (2004) 304.

[12] P.J. Jacques, J. Ladrière, F. Delannay, Metall. Mater. Trans. A 32A (2001) 2759.

[13] D.A. Porter, K.E. Easterling, Phase Transformations in Metals and Alloys, Chapman \& Hall, London, 1992.

[14] H. Hasegawa, D.G. Pettifor, Phys. Rev. Lett. 50 (1983) 130.

[15] K.W. Andrews, J. Iron Steel Inst. 203 (1965) 721.

[16] J.W. Christian, The Theory of Transformations in Metals and Alloys, third ed., Pergamon Press, Oxford, 2002. 